\title{
Which Armenian Higher Education Institutions Are Visible on ResearchGate?
}

\author{
Vardan Atoyan (1) \\ AMBERD Research Center, Armenian State University of Economics, Yerevan, Armenia \\ Email: atoyan.amberd@asue.am
}

How to cite this paper: Atoyan, V. (2020). Which Armenian Higher Education Institutions Are Visible on ResearchGate? Open Journal of Social Sciences, 8, 243-251. https://doi.org/10.4236/jss.2020.86021

Received: May 6, 2020

Accepted: June 12, 2020

Published: June 15, 2020

Copyright $\odot 2020$ by author(s) and Scientific Research Publishing Inc. This work is licensed under the Creative Commons Attribution International License (CC BY 4.0).

http://creativecommons.org/licenses/by/4.0/

\section{(c) (i) Open Access}

\begin{abstract}
In the digital era, technological transformations and rapid development of internet platforms create immense possibilities for the academic community and students to get knowledge, transfer, disseminate, generate new ideas and establish new collaborations. Different platforms of knowledge accumulation and dissemination are rapidly being developed and improved in the internet. Network academic communities are established that join professionals having the same interests and facilitate the process of exchange of research products and deliverables. In this regard, one of the well known platforms is ResearchGate. Considering the above mentioned, the author of the article aims at exploring the level of representation of Armenian higher education institutions at ResearchGate network. The Article also touches upon the remarks among academic community regarding RG Score reputation index developed by ResearchGate. Multiplicative effect interconnected to the activeness of representatives of higher education institutions in such platforms was described. As a result of the current research, it was drawn out that Armenian universities are not presented sufficiently at ResearchGate platform. Moreover, majority of Armenian higher education institutions do not have an institutional profile in the presented platform. Possible reasons of weak representation were analyzed.
\end{abstract}

\section{Keywords}

ResearchGate, RG Score, Armenia, Higher Education Institutions, Institutional Profiles

\section{Introduction}

During the last decades, technological development and economic, political, social and other sphere transformations conditioned with the latter bring new issues in education, among its higher education system modernization. It is well 
known that the educational system has mostly conservative nature and is endowed with institutional inertia which sometimes complicates implementation of in-depth reforms with adequate flexibility and speed. Nevertheless, ever-changing processes and changing labor market demands of XXI century force actors of the education sector to follow their own rules of the game. Increasing competition forces the universities to modernize permanently for increased attractiveness among potential students, diversification of funding sources, improvement of level of educational services and solving the issues of improving their academic reputation successfully. In such tough competition, only those higher education institutions (HEI) will succeed which will meet challenges, meet the expectations of main beneficiaries and will meet the requirements of the modern digital era.

At the same time, technological transformations and rapid development of the internet platforms create immense possibilities for students and academic community to create knowledge, transfer it, disseminate, generate new ideas and establish new collaborations. Different platforms of knowledge accumulation and dissemination are elaborated and developed rapidly in the digital domain. Network academic communities are established which join professionals bearing the same interests and facilitate the process of exchange of research products and research deliverables. In this regard, one of the most popular platforms is ResearchGate (RG) professional social network established in 2008 by physicians Dr. Ijad Madisch and Dr. Sören Hofmayer, and computer scientist Horst Fickenscher.

The purpose of this study was to investigate the presence and activeness of Armenian university community in RG. Results of the research may be useful for the responsible staff of the research area, decision makers and university management of Armenia to elaborate related development strategies.

\section{Methodology}

Acting universities of the Republic of Armenia were identified from the official web site of the Ministry of Education, Science, Culture and Sport of the Republic of Armenia, as of April 10, 2020. RG Scores of Armenian HEIs having institutional profiles in RG were also discussed.

It is important to mention that in some cases the universities greatly differ in their size of the staff, number of the faculty and students. In that case by only presenting RG Score of HEIs it is possible to have a not that complete quality picture. To have a comparably objective picture of activeness of Armenian HEIs the author counted and presented in a separate table the HEIs having more than 50 members and more than 100 RG Score in RG network the Score presenting per 1 member. Details as of $23^{\text {rd }}$ of April, 2020 at RG platform are considered for the analysis.

It is necessary to add that National Polytechnic University of Armenia is in fact represented with two institutional profiles in RG. The issue probably is conditioned with the representatives of the university-they have not updated in- 
formation regarding their affiliation and are registered with the ex name of the mentioned HEI as representative of State Engineering University of Armenia. As a result two different institutional profiles of one university were generated in RG platform. Considering that multiple affiliations are not allowed in RG and in that case double calculation is excluded in the frames of the current survey indexes of the above mentioned two profiles were added and represented as indexes of National Polytechnic University of Armenia.

Almost the same issue is in the case of Yerevan Brusov State University of Languages and Social Sciences. The latter is represented with the ex name of the university in the profile Yerevan State Linguistic University. It may be assumed that the representatives registered with the affiliation of the mentioned university have not updated the information about the HEI in their own profiles. It is also worth mentioning that in contrast to National Polytechnic University of Armenia, which as mentioned is represented with two institutional profiles with the new and ex names, there is no institutional profile in RG with the current name. Therefore, as indexes of Yerevan Brusov State University of Languages and Social Sciences the author considered results of the ex institutional profile.

In addition, the current article analyzes some remarks regarding the RG Score by the academic community.

\section{Results}

As a result of carried research it became obvious that out of more than 60 HEIs and their branches currently active in Armenia only 13 have their institutional profiles registered in RG. Considering the above mentioned it may be concluded that no representative of other HEIs is registered in RG network or is registered but the institutional affiliation is not mentioned. This may be the reason that RG did not generate an institutional profile for the mentioned HEIs. Table 1 depicts the number of representatives from all Armenian HEIs and total RG Score of the HEIs.

As it is seen from data of the table that 6 out of 13 represented HEIs having profiles in RG have rather modest representation, from 2 to 34 users, and RG Score of the mentioned HEIs varies from 0 to 32. These are Armenian State University of Economics, Haybusak University of Yerevan, National University of Architecture and Construction of Armenia, Yerevan Brusov State University of Languages and Social Sciences, Eurasia International University, Yerevan Gladzor University. RG Score per 1 member of 7 Armenian HEIs having rather notable presence in RG is represented in Table 2 below.

As it is depicted in Table 2 in this case the picture and order of the HEIs is mostly changed. When referring the mentioned results it is necessary to consider that student-faculty ratio may differ at universities and/or students of any HEI may be more active users at RG and outnumber faculty representatives. Student users are mostly consumers of research product and not generators of research 
Table 1. Armenian HEIs on ResearchGate (As of April 23, 2020).

\begin{tabular}{cccc}
\hline & Higher Education Institutions & Members Total RG Score \\
\hline 1 & Yerevan State University & 1023 & 4016.29 \\
2 & Yerevan State Medical University after Mkhitar Heratsi & 134 & 591.73 \\
3 & American University of Armenia & 779 & 558.09 \\
4 & National Polytechnic University of Armenia & 108 & 344.24 \\
5 & Russian-Armenian (Slavonic) University & 106 & 307.65 \\
6 & Armenian National Agrarian University & 82 & 274.68 \\
7 & Armenian State Pedagogical University after Khachatur Abovyan & 100 & 199.52 \\
8 & Armenian State University of Economics & 34 & 31.44 \\
9 & Haybusak University of Yerevan & 4 & 19.05 \\
10 & National University of Architecture and Construction of Armenia & 13 & 14.00 \\
11 & Yerevan Brusov State University of Languages and Social Sciences & 21 & 2.83 \\
12 & Eurasia International University & 5 & 1.20
\end{tabular}

Table 2. Table of HEIs having RG score per 1 member (As of April 23, 2020).

\begin{tabular}{lcc}
\hline & Higher Education Institutions & RG Score per 1 member \\
\hline 1 & Yerevan State Medical University after Mkhitar Heratsi & 4.41 \\
2 & Yerevan State University & 3.92 \\
3 & Armenian National Agrarian University & 3.34 \\
4 & National Polytechnic University of Armenia & 3.18 \\
5 & Russian-Armenian (Slavonic) University & 2.90 \\
6 & Armenian State Pedagogical University after Khachatur Abovyan & 1.99 \\
7 & American University of Armenia & 0.71 \\
\hline
\end{tabular}

product. Therefore, their personal RG Score usually is not high as the latter is formed also on the bases of scores of the research impact. As a result, the quantitative dominance of student users in RG over faculty representatives of the same university can significantly affect the overall RG Score per 1 member of the HEI. Nevertheless, also other factors may impact which could be the subject of another research.

\section{Discussion}

Currently RG network has more than 17 million members ("ResearchGate", April 25, 2020). It is one of the most reputable social networks available for free to discuss and debate the researchers (Asemi \& Heidari, 2018: p. 151). The current platform gives possibility to share publications, to present completed and current projects, search for publications, rate and comment those, find scholars with the similar research interests, communicate and cooperate with colleagues, 
initiate and participate in discussions, ask questions to the academic community and get answers. Vacancies and conference invitations are also available in RG platform.

It is worth mentioning that RG platform may be used during the educational processes. Students and young researchers may freely use millions of research products available in the network, accumulate and generate new ideas but also get valuable advice from the academic community through active involvement and networking. In this context method developed by Igor Gurkov and Zokirzhon Saidov may be mentioned, the aim of which is formation of skills and competences of formulating questions not having unequivocal answers that are of interest among RG network academic society (Gurkov \& Saidov, 2019).

One of the unique things about RG network is RG Score. As described in its explanation "The RG Score measures scientific reputation based on how your work is received by your peers. Personal RG Score is calculated based on any contribution each member shares on ResearchGate or add to personal profile, such as published articles, unpublished research, projects, questions, and answers. ResearchGate algorithm looks at how your peers receive and evaluate these contributions, and who they are. The higher the RG Scores of those who interact with your research, the more your own score will increase" ("ResearchGate", April 15, 2020).

Recorded indicators of each HEIs representative is generated by the RG platform and it is jointly depicted in the profile of the HEIs (aggregate the achievements of affiliated). As a result each HEI also gets RG Score, which is generated by the accumulation of RG Scores of the representatives of the mention HEI. Institutional profiles of the HEI contain brief information about the particular institution, affiliated members, cumulative number of publications uploaded by them, most popular publications, and other important information for analysis.

It is worth mentioning there is no definite attitude towards RG Score in the frames of academic community. Though the calculation algorithm of RG Score is under improvement periodically critics towards RG Score are not few. In particular as criticism it is mentioned that the items taken into account to construct the RG score and their relationships are still unknown (Copiello \& Bonifaci, 2019: p. 1257), and the lack of transparency in the calculation of the different metrics (especially the RG Score) prevents it from being useful, since they cannot be replicated (Martín-Martín et al., 2016: p. 54).

Besides, the RG score only accounts for interactions on that particular site whereas activities may be distributed across different social media platforms (Jordan, 2015). Other researchers mention that RG Scores are so highly correlated with the volume of WoS publications that they should not be used for comparisons or for ranking institutions for research quality, because larger institutions will tend to have an unjustifiably high research performance ranking (Lepori et al., 2018).

Some critics regarding RG Score also refer to possible manipulations by some users. Researchers mention that the manipulation of RG Scores by some authors 
may jeopardize the utilization of this metric for evaluative purposes, even with pure academic users (Orduna-Malea et al., 2017).

It is also considerable that users of RG differ in being active and their motivation to become members of the network. Difference of active involvement of RG members in the platform is explained by the researchers also considering the institutional factor. Researchers mention that more active users of RG network are mostly from developing countries which they explain with less possibilities of the latter for self development, participation in conferences and working at advanced scientific centers and they try to compensate it with active involvement in RG and participation in academic discussions (Khvatova \& Dushina, 2020). Besides, many members do not fully engage with the social/community side of the platform and tend to use it just as a resource discovery or a publications showcase (Nicholas et al., 2016: p. 87).

As we may see there isn't a lack of critics towards RG Score. It should be agreed that in most cases those are of objective nature. Nevertheless, it is worth mentioning that comprehensive, complete, objective and involving all factors, facts and circumstances in exact proportion of development of academic reputation index is a complicated issue if not an impossible one.

Besides it should be accepted that as an academic reputation index RG Score has its importance at least to have general notion if not considered an official one both in case of an individual researcher and HEI. Especially in the case where in the base of its formation are also famous indexes of academic activeness regarding publications, citations, etc. Also considering the fact that RG is one of the most popular professional social platforms in the world, the very low or high RG Score may depict the real picture of the current research activity of the HEIs. In addition many opportunities, the function of knowledge generation and dissemination and the fact that RG mainly promotes Open Science may not be ignored.

Nevertheless, the main aim of the current research is not participation in academic debate in the frames of RG Score but revelation of research activity and visibility of Armenian HEIs in RG. RG Scores of Armenian HEIs in general express the current situation. In this context it is necessary to mention that during the Soviet period academic activity was mainly focused in the system of research institutions under the Academy of Sciences (current National Academy of Sciences) and the main function of HEIs was delivery of educational services. This reality still retains its momentum and up to now research and development mainly concentrated in the different institutes of National Academy of Sciences of Armenia. However, after the declaration of independence situation is improving gradually. In particular, by the support of the Government and efforts of the university leaders though some steps are taken, mechanisms and tools are elaborated that give opportunity to foster and promote scientific and research activities (Atoyan, 2015: p. 58). Many research centers, laboratories, think tanks are established at different Armenian universities. Many Armenian universities stopped being institutions providing the students just existing knowledge and 
delivering education services: they gradually do their best to assume the function of research institutions (Atoyan et al., 2015). Hence, one may assume that in line with increasing research activeness of Armenian HEIs level of representation of the latter at RG will also increase gradually.

Current results show that in comparative terms the community of Armenian HEIs is not that active in RG platform and poorly presented. Only RG Score of the leading Armenian HEI - Yerevan State University is comparatively close to some leading universities of post-soviet space. For example as of April 23, 2020 Total RG Score of National Research University Higher School of Economics was 9141.25, Belarusian State University-6513.48, Ivane Javakhishvili Tbilisi State University—4851.75, National Taras Shevchenko University of Kiev—8943.39. For comparison it is worth to also mention that the RG Score of Lomonosov Moscow State University was 60,920.95 as of the same date.

Nevertheless, there are also optimistic processes. Some Armenian HEIs gradually make their presence in such platforms as priority. It is also mentioned in official documentation and are referred as strategic. For example Armenian State University of Economics (ASUE) is preparing to develop activity plan for 2020 to provide presence of publications of all scholars of the university in Google Scholar, ResearchGate and Academia.edu platforms ("ASUE, Annual Report 2019”, 2020: p. 21).

\section{Conclusion}

Concluding the article, it is drawn out that Armenian HEIs do not show sufficient activeness in RG platform in general. Basis of the conclusion is the fact that most of the Armenian HEIs do not have an institutional profile in the RG platform and the HEIs that have profile mostly show very low index. One may assume the issue is not only conditioned with the lack of research capacities. Institutional development, research capacity building, improvement of knowledge and skills of HEI staff are the issues to be taken into account and advanced permanently. Research capacity of Armenian HEIs is bigger compared to indexes currently depicted in RG platform. There is a necessity to elaborate and adopt motivational mechanisms to promote individual activeness of HEI affiliated scholars in the platforms like above mentioned. This may provide complementary, multiplicative and reputation benefits both for the researchers and HEIs. Active engagement of researchers may increase recognition, attractiveness of HEIs, improve level of internationalization, expansion of partnerships' network, dissemination of research results, increasing number of citations, etc. Therefore, in case of implementing fostering policy and applying appropriate approaches, current indexes of Armenian HEIs in RG platform may be improved relatively fast.

The current research was an attempt to draw attention on this issue, shed light on the current situation, present representation and main indexes of Armenian HEIs at RG, and highlight some issues and trends of the sector. Results of the 
implemented research may be the base for further research and be useful while elaborating development strategies of HEIs. During the upcoming researches of the current topic, it will be necessary to analyze also the dynamics of representation, activeness, change of indexes of Armenian HEIs at RG and elaborate recommendations.

\section{Acknowledgements}

The author expresses his gratitude to his friend and ex colleague Ms. Vard Ghukasyan, Ex Head of the International Relations Office of Armenian State University of Economics for supporting in proofreading the Article.

\section{Conflicts of Interest}

The author declares no conflicts of interest regarding the publication of this paper.

\section{References}

Asemi, A., \& Heydari, M. (2018). Correlation between the Articles Citations in Web of Science (WoS) and the Readership Rate in Mendeley and Research Gate (RG). Journal of Scientometric Research, 7, 145-152. https://doi.org/10.5530/jscires.7.3.25

ASUE (Armenian State University of Economics) (2020). Annual Report 2019. https://asue.am/upload/files/asue-report-2019.pdf

Atoyan, V. (2015). University Affiliated Think Tanks in Armenia. Austrian Journal of Humanities and Social Sciences, 11-12, 58-59. https://doi.org/10.20534/AJH-16-11.12-58-59

Atoyan, V., Ohanyan, S., \& Makljyan, A. (2015). Development Prospects of Armenian University Affiliated Think Tanks: AMBERD Research Center. Almanach Via Evrasia, 4.

http://www.viaevrasia.com/en/15-development-prospects-of-armenian-university-affili ated-think-tanks-amberd-research-center-vardan-atoyan-sofya-ohanyan-arpine-maklj yan.html

Copiello, S., \& Bonifaci, P. (2019). ResearchGate Score, Full-Text Research Items, and Full-Text Reads: A Follow-Up Study. Scientometrics, 119, 1255-1262.

https://doi.org/10.1007/s11192-019-03063-6

Gurkov, I., \& Saidov, Z. (2019). Methodology of Posting Questions on ResearchGate for Students-Part 1. https://doi.org/10.13140/rg.2.2.34435.76329

Jordan, K. (2015). Exploring the ResearchGate Score as an Academic Metric: Reflections and Implications for Practice. Quantifying and Analysing Scholarly Communication on the Web (ASCW'15), Oxford, 30 June 2015, forthcoming. http://ascw.know-center.tugraz.at/wp-content/uploads/2015/06/ASCW15_jordan_resp onse_kraker-lex.pdf

Khvatova, T., \& Dushina, S. (2020). Scientific Online Communication: The Strategic Landscape of ResearchGate Users. International Journal of Technology and Human Interaction, Special Issue Submission: Technology \& Innovation: A Half-Century of Internet-Enabled Change, 17, Article 6.

Lepori, B., Thelwall, M., \& Hoorani, B. H. (2018). Which US and European Higher Education Institutions Are Visible in ResearchGate and what Affects Their RG Score? Journal of Informetrics, 12, 806-818. https://doi.org/10.1016/j.joi.2018.07.001 
Martín-Martín, A., Orduna-Malea, E., Ayllón, J. M., \& Delgado López-Cózar, E. (2016). The Counting House: Measuring Those Who Count. Presence of Bibliometrics, Scientometrics, Informetrics, Webometrics and Altmetrics in the Google Scholar Citations, ResearcherID, ResearchGate, Mendeley \& Twitter. EC3 Working Papers, 21. https://arxiv.org/ftp/arxiv/papers/1602/1602.02412.pdf

Ministry of Education, Science, Culture and Sport of the Republic of Armenia. (n.d.). Retrieved 10 April 2020. http://escs.am/am/category/listings

Nicholas, D., Herman, E., \& Clark, D. (2016). Scholarly Reputation Building: How Does ResearchGate Fare? International Journal of Knowledge Content Development \& Technology, 6, 67-92. https://doi.org/10.5865/IJKCT.2016.6.2.067

Orduna-Malea, E., Martín-Martín, A., Thelwall, M., \& López-Cózar, E. D. (2017). Do ResearchGate Scores Create Ghost Academic Reputations? Scientometrics, 112, 443-460. https://doi.org/10.1007/s11192-017-2396-9

ResearchGate (n.d.). Retrieved 15 April 2020. https://explore.researchgate.net/display/support/RG+Score

ResearchGate (n.d.). Retrieved 25 April 2020. https://www.researchgate.net/about 